(RESEARCH ARTICLE)

\title{
Feed value of fermented spent sorghum grains for broiler chickens
}

\author{
Onyimba Isaac Amechi * \\ Department of Science Laboratory Technology, University of Jos, Nigeria.
}

Publication history: Received on 21 April 2020; revised on 27 April 2020; accepted on 29 April 2020

Article DOI: https://doi.org/10.30574/wjarr.2020.6.1.0116

\begin{abstract}
In view of rising cost of conventional broiler chicken feeds in Nigeria, the value of fermented spent sorghum grains (FSSG) as alternative feed for broiler chickens was evaluated. Sterilized, spent sorghum grains were fermented for 21 days at $25 \pm 2{ }^{\circ} \mathrm{C}$ using a consortium of Aspergillus niger, Chaetomium globosum and Saccharomyces cerevisiae. Five test diets were formulated by supplementing commercial chicken broiler feed (CBD) with the FSSG at 0, 5, 10,15, and 100\% levels. Proximate contents of the diets were determined. A 28-day Feeding experiment was carried out in a completely randomized design in which 40 day-old broiler chicks were assigned to the five dietary treatments. Eight birds were allocated to each treatment with two replicates of 4 birds each. Parameters monitored included feed intake, weight gain, feed efficiency ratio (FER) and protein efficiency ratio (PER). Higher amounts of FSSG in the diets resulted in significantly higher $(P<.05)$ crude protein and crude fibre contents and lower NFE content and feed intake. The highest average weight gain of $21.61 \mathrm{~g} / \mathrm{bird} /$ day was recorded for the 5\% FSSG diet. This diet also brought about the highest FER of 0.58 . The PER (2.51) of the 5\% FSSG diet was insignificantly lower $(P>.05)$ than the value $(2.60)$ recorded for CBD. The findings showed that fermented spent sorghum grains, when used solely, cannot serve as alternative feed for broiler chickens. However, conventional chicken feed could be supplemented with fermented spent sorghum grains at $5 \%$ level without negative effects on broiler performance.
\end{abstract}

Keywords: Fermented; Spent sorghum grains; Feed value; Broilers, Chicken

\section{Introduction}

The cost of major conventional feedstuffs such as maize and soya bean has continued to rise in Nigeria, making the cost of finished feeds to be prohibitive. In view of this rising cost, the sole use of these conventional feed ingredients for intensive animal production is no longer justifiable. Inclusion of alternative non-conventional feed resources in animal feed has been advocated as a way out of this nutritional crisis [1]. Crop residues and agro industrial byproducts abound in Nigeria [2]. Some of these wastes are left underutilized, and become sources of environmental pollution. Those that are utilized do not have their full potentials harnessed [3]. These wastes have been explored as possible alternatives to conventional feedstuffs.

The potential for use of many non-conventional materials as feed or as inputs for feed production is limited by some factors one of which is their fibrous nature which limits their feed value especially for non-ruminant animals. High crude fibre content of FARs limits voluntary intake and utilization especially in monogastrics.

Physical, chemical and biological treatments have been used to upgrade fibrous agro- wastes for different uses including use as animal feed. In view of stricter environmental regulations and the unacceptability of some existing treatment methods, biological treatment is the preferable approach for upgrading of solid agricultural wastes for animal feed uses [4]. The present work sought to determine the feed value of spent sorghum grains fermented with a consortium of Aspergillus niger, Chaetomium globosum and Saccharomyces cerevisiae for broiler chickens.

\footnotetext{
${ }^{*}$ Corresponding author: Onyimba Isaac Amechi
} 


\section{Materials and methods}

\subsection{Sample collection and preparation}

Spent sorghum grains were obtained from the Jos International Brewery in Jos South LGA of Plateau State. Twentygramme weights of the grains were transferred into $250 \mathrm{ml}$ conical flasks and moistened with $35 \mathrm{ml}$ of sterile distilled water. A spatula was used to thoroughly mix the contents of the flasks. The mouth of each flask was then fitted with an aeration apparatus which consisted of a rubber cork with two glass tubes running through its middle. The outer ends of the glass tubes were plugged with cotton wool and then covered with aluminium foil. The flasks together with aeration apparatus were autoclaved for a period of 15 minutes at $121^{\circ} \mathrm{C}$ and $1 \mathrm{kgcm}^{2}$, after which they were allowed to cool to room temperature.

\subsection{Fermentation of spent sorghum grains}

Fermentation of spent sorghum grains was carried out using the method employed by [5]. With the aid of sterile pipettes, the sterilized grains in each of the flasks were inoculated with $3 \mathrm{ml}$ of inoculum containing $2.14 \times 10^{6}$ spores of A. niger, $2.34 \times 10^{6}$ spores of Chaetomium globosum and $2.64 \times 10^{6}$ cells of Saccharomyces cerevisiae. The inoculated samples were mixed thoroughly with the aid of a sterile spatula. This helped to make sure that the fungal spores and yeast cells were evenly distributed. The pieces of aluminium foil covering the mouths of the glass tubes of the aeration apparatus were removed and the inoculated substrates were allowed to ferment aerobically over a period of 21 days at $25 \pm 2^{\circ} \mathrm{C}$. At the end of the fermentation period, microbial activity was terminated by subjecting the fermented substrate to tyndalization. The substrate was then dried at $60^{\circ} \mathrm{C}$ in a hot air oven, blended with the aid of a sterilized domestic blender and then stored in sterile air-tight glass jars.

\subsection{Experimental diets}

A total of five diets were used in the experiment. The diets included two basic diets and three composite diets. The basic diets were commercial broiler chicken feed (CBD) which served as the control diet, and $100 \%$ fermented spent sorghum grains diet (FSSG). The remaining three diets were obtained by supplementing CBD with FSSG at 5, 10, and 15\% levels. The proximate contents of all the diets were determined using the method of [6].

\subsection{Feeding trials with experimental diets}

Forty day-old broiler chicks of about same weight were procured from Zartech Farms in Jos. The birds were divided into two groups of 20 each. The first group of 20 birds was subdivided into five groups of four birds each and each group was housed in a cage. Each group of birds was then randomly placed on one of the following five diets: Commercial chicken broiler feed (CBD) which served as the control diet; 100\% fermented spent sorghum grains diet (100\% FSSG); $5 \%$ fermented spent sorghum grains diet (5\% FSSG); 10\% fermented spent sorghum grains diet (10\% FSSG); and 15\% fermented spent sorghum grains diet (15\% FSSG). The birds were fed with the control and other diets for a period of 28 days within which free access to diet and water was allowed. The whole experiment was repeated with the second group of 20 birds. During the feeding period, records of daily feed intake and weekly weight gains or losses were recorded. Growth rate, Feed Efficiency Ratio (FER) and Protein Efficiency Ratio (PER) were determined using standard formulae.

\subsection{Statistical analysis}

The results obtained were subjected to one-way anova statistical analysis with the aid of Microsoft Excel version 2010 software. P-values less than .05 were considered significant. Least Significant Difference (LSD) was used to compare means.

\section{Results}

\subsection{Proximate composition of formulated diets}

The crude protein contents of the 5\%,10\%,15\%, and 100\% fermented spent sorghum grains (FSSG) diets were found to be higher than that of the control commercial broiler diet (CBD). Protein contents ranged from 21.97-43.42\%, increasing with increase in the percentage of the fermented grains in the diet. Crude fibre contents also increased with increase in the amount of fermented spent grains present in the diets, ranging from $6.50-18.09 \%$. The $100 \%$ FSSG diet had the highest crude protein and crude fibre contents $(43.42 \%$ and $18.09 \%$ respectively) while CBD had the lowest contents in both parameters $(21.97 \%$ and $6.50 \%$ respectively). Increases in the amount of fermented grains in the diets 
led to decreases in the content of nitrogen free extract (NFE) which ranged from 18-54.59\% with 100\% FSSG having the lowest value and CBD having the highest. The contents of crude fat and ash were comparable for all the diets. The differences in the crude protein, crude fibre, and NFE contents of the different diets were statistically significant $(P<$ .05). Details of the proximate compositions of the different diets fed the birds are given in Figure 1.

\subsection{Effect of diet on broiler chicken performance parameters}

Commercial broiler feed (CBD) was the most consumed (37.69g/bird/day) of all the diets. Feed intake decreased as inclusion level of the fermented grains increased. The reductions in feed intake were found to be statistically significant at $P<.05$.

The highest average weight gain of $21.61 \mathrm{~g} / \mathrm{bird} /$ day was recorded for the $5 \%$ fermented spent sorghum grains diet ( $5 \%$ FSSG). The commercial feed was next in terms of weight gain with a value of $21.49 \mathrm{~g} / \mathrm{bird} / \mathrm{day}$. The observed difference in weight gain between CBD and the 5\% FSSG diet was, however, not statistically significant (P $>0.05)$. Feeding the experimental broiler chickens with the diets containing $10 \%$ and above of the fermented grains led to significantly lower weight gains in the broilers. The 5\% FSSG diet brought about the highest Feed Efficiency Ratio (FER) of 0.58 . The diets which contained above $5 \%$ of the fermented grains brought about lower values for FER and PER. The values for FER and PER were found to decrease with increase in the level of the fermented grains in the diets. Negative values were recorded for weight gain, FER and PER for the 100\% FSSG diet. All the broiler chicken fed strictly on 100\% FSSG died within a period of five days. Details of feed intake, weight gain, FER and PER values of the experimental chicken broilers are shown in Figure 1.

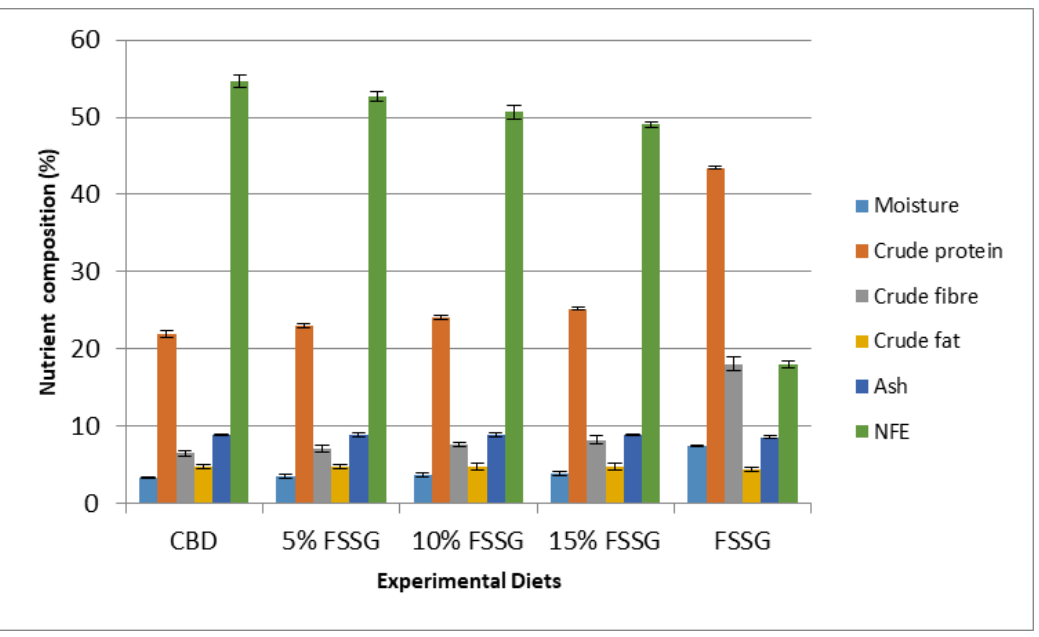

Figure 1 Nutrient Composition of diets fed the Experimental broiler chickens. Key: CBD = Commercial broiler feed, FSSG $=$ Fermented spent sorghum grains

Table 1 Feed intake, protein intake, weight gain, feed and protein efficiency ratios in broiler chickens fed diets containing different levels of fermented spent sorghum grains

\begin{tabular}{|c|c|c|c|c|c|}
\hline \multirow[t]{2}{*}{ Nutrients } & \multicolumn{5}{|c|}{ Diets (\% Upgraded spent sorghum grains) } \\
\hline & $\mathrm{A}(0 \%)$ & $\mathrm{B}(5 \%)$ & $\mathrm{C}(10 \%)$ & $\mathrm{D}(15 \%)$ & $\mathrm{E}(100 \%)$ \\
\hline $\begin{array}{l}\text { Feed Intake } \\
\text { (g/bird/day) }\end{array}$ & $37.69 \pm 0.10^{\mathrm{a}}$ & $37.43 \pm 0.25^{\mathrm{a}}$ & $34.80 \pm 0.40^{b}$ & $32.20 \pm 0.07^{c}$ & $2.48 \pm 0.20^{\mathrm{d}}$ \\
\hline $\begin{array}{l}\text { Protein ntake } \\
\text { (g/bird/day) }\end{array}$ & $8.28 \pm 0.10^{\mathrm{a}}$ & $8.62 \pm 0.05^{\mathrm{a}}$ & $8.39 \pm 0.07 \mathrm{a}$ & $8.11 \pm 0.04^{\mathrm{a}}$ & $1.08 \pm 0.09 \mathrm{~b}$ \\
\hline $\begin{array}{l}\text { Weight Gain } \\
\text { g/bird/day }\end{array}$ & $21.49 \pm 0.20^{\mathrm{a}}$ & $21.61 \pm 0.50^{\mathrm{a}}$ & $17.10 \pm 0.40^{b}$ & $32.20 \pm 0.07 \mathrm{c}$ & $-2.87 \pm 0.70^{\mathrm{d}}$ \\
\hline FER $^{*}$ & $0.57 \pm 0.01^{\mathrm{a}}$ & $0.58 \pm 0.02^{\mathrm{a}}$ & $0.49 \pm 0.01^{\mathrm{ab}}$ & $0.43 \pm 0.03^{b}$ & $-1.16 \pm 0.10^{c}$ \\
\hline PER $^{\circ}$ & $2.60 \pm 0.02^{\mathrm{a}}$ & $2.51 \pm 0.05^{\mathrm{a}}$ & $2.04 \pm 0.05^{b}$ & $1.70 \pm 0.04^{c}$ & $-2.66 \pm 0.04^{d}$ \\
\hline
\end{tabular}

\footnotetext{
${ }^{*}$ Feed efficiency ratio, ${ }^{\circ}$ Protein efficiency ratio; Means on same row with different superscripts are significantly different ( $P=.05$, Anova Data are means $\pm S D(n=4)$
} 


\section{Discussion}

\subsection{Proximate composition of experimental diets}

Diets that had higher contents of fermented spent sorghum grains were found to have higher crude protein contents. The higher crude protein content of these diets was probably due to single cell protein production during fermentation of the spent sorghum grains. Aspergillus niger and Chaetomium globosum are known to be cellulolytic and as such, would naturally break down the cellulose component of the grains into simple sugars which could have been used by the microorganisms in the consortium for protein synthesis and cellular growth. [7] and [8] reported that fermentation of soya bean products and mucuna beans flour respectively led to similar increases in the protein contents of the substrates. Increase in the protein content of brewers dried grains degraded by Aspergillus flavus was also reported by [9].

The results showed that higher amounts of fermented spent grains in the diets resulted in higher crude fibre contents. Though solid state fermentation of agro-industrial byproducts brings about reductions in crude fibre content [3,5 and 9], it is evident that the $18.09 \%$ crude fibre content of the $100 \%$ FSSG remains significantly higher than the $6.5 \%$ crude fibre content of the commercial broiler feed (CBD). Supplementation of the commercial feed with the fermented grains would invariable result in higher crude fibre contents of the resultant diets.

The observed decreases in nitrogen-free-extract (NFE) values which accompanied increases in the amount of fermented grains in the diets may be as a result of the lower NFE content of the fermented spent sorghum grains (FSSG). In fungal biodegradation of agro-industrial byproducts, NFE content tends to increase at the earlier stages of fermentation due to breakdown of complex carbohydrates to simpler ones. As fermentation time increases, NFE content gradually decreases because simple carbohydrates are used up by the microbial cells for their metabolic activities such as synthesis of cellular components. [10] reported that the soluble carbohydrate values of agro-industrial byproducts fermented with species of Aspergillus and Penicilium decreased after 14 days of solid state fermentation with Trichoderma viride.

\subsection{Effects of test diets on broiler chicken performance parameters}

The highest average daily feed intake (37.69 g/bird/day) by the broiler chickens was recorded for the commercial feed (CBD). The 5\% fermented grains diet was next in terms of feed intake. The difference in feed intake between the control diet and the $5 \%$ fermented grains diet was not statistically significant $(P>.05)$. Feed intake decreased as the amounts of the fermented substrate in the diets increased. [11] similarly reported that the incorporation of Atella, a local brewing waste, into poultry feed led to decreases in the feed intake of the birds. The lower feed intake observed in the chicken broilers fed the diets which contained the fermented grains could be attributed to high crude fibre contents of the diets (Figure 1). High crude fibre content reduces digestibility and voluntary intake [11]. Also, the diets may not have been palatable for the chickens. Improving the palatability of the fermented grains may improve feed intake. The use of flavour agents such as molasses, aspartame, citric acid and saccharin have been suggested for improvement of feed palatability [12].

The 5\% FSSG diet was found to be the best feed for the broiler chickens. It brought about the highest average daily weight gain of $21.61 \mathrm{~g} /$ bird/day and the highest Feed Efficiency Ratio (FER) of 0.58 (Table 1). It was closely followed by the control commercial diet in terms of the two parameters. Though the higher weight gain observed for the $5 \%$ FSSG diet over the commercial feed was not statistically significant, it remains relevant from the point of view of animal production.

Above the 5\% FSSG inclusion level, weight gain, FER, and PER decreased progressively. The findings here are in agreement with those of [13], [11] and [14]. These authors reported that incorporation of high levels of fermented agricultural residues into chicken feed led to decreases in weight gain, FER and PER. The lower performances observed in the broiler chickens fed diets containing higher levels of the fermented spent grains could have resulted from the low feed intake observed in the broilers fed such diets. This low feed intake probably resulted in lack of adequate nutrients to meet the requirements for good growth of the chickens. High crude fibre content also leads to non-optimal utilization of ingested nutrients. According to [15], unavailability of dietary protein can be caused by excessive dietary fibres which disturb digestive enzyme action by binding to minerals and B group vitamins that usually act as enzyme cofactors in protein metabolism. The mortality observed in the broilers that were fed the $100 \%$ FSSG diet was probably as a result of starvation. This is evidenced by the very low feed intake by the broilers. 
The better performance observed in the chicken broilers fed the 5\% FSSG diet can be attributed to a number of factors. At this low level of inclusion of the fermented material, whatever palatability problem that might have existed could have been overshadowed by the larger quantity of commercial feed present in the diets. Also, the low amount of fermented grains in the diet may not have posed any significant digestibility problem. These factors would lead to good feed intake. The higher crude protein content of the 5\% FSSG over that of the control commercial feed could have contributed to the feed acceptability and the higher weight-gains observed in the broilers fed on it. Fermented spent sorghum grains have also been shown to contain adequate levels of most of the essential amino acids required for growing chicken broilers [5].

\section{Conclusion}

Spent sorghum grains fermented with a consortium of Aspergillus niger, Trichoderma viride, and Chaetomium globosum is not a good quality feed for broiler chickens when used solely. Broilers fed solely on the $100 \%$ fermented spent sorghum grains diet performed poorly in terms of weight gains, feed and protein efficiency ratios. Conventional commercial broiler feed supplemented with $5 \%$ of the fermented spent sorghum grains brought about better broiler performance over all the other diets including the commercial feed and as such is a good feed for broiler chickens. The higher the amount of the fermented grains that can be tolerated in chicken broilers diet, the lower the cost of production. It is needful to further reduce the crude fibre content of the fermented grains. This could lead to improved digestibility and better intake, which in turn, would enhance the feed value of fermented spent sorghum grains for broiler chickens.

\section{Compliance with ethical standards}

\section{Acknowledgments}

Author is grateful to Mr. Bulus H. Jatau of the National Veterinary Research Institute Vom for his technical assistance.

\section{Disclosure of conflict of interest}

Author has declared that no conflict of interests exists.

\section{Statement of ethical approval}

Ethical approval for the study was obtained from the University of Jos Institutional Ethical Committee on the Use of Animals.

\section{References}

[1] Amata IA. (2014). The use of nonconventional feed resource (NCFR) for livestock feeding in the tropics: A review. Journal of Global Biosciences, 3(2), 604-613.

[2] Simonyan KJ and Fasina O. (2013). Biomass resources and bioenergy potentials in Nigeria. Journal of Agricultural Research, 8(40), 4975-4989.

[3] Iyayi EA. (2004). Changes in the cellulose, sugar and crude protein contents of agro-industrial by-products fermented with Aspergillus flavus and Penicillium sp. African Journal of Biotechnology, 3(3), 186-188.

[4] Mahesh MS and Madhu M. (2013). Biological treatment of crop residues for ruminant feeding: A review. African Journal of Biotechnology, 12(27), 4221-4231.

[5] Onyimba IA, Ogbonna CIC, Akueshi CO, Chukwu CO and Ogbonna AI. (2014). Microbial processing of spent sorghum grains for possible used as chicken feed. IOSR Journal of Pharmacy and Biological Sciences, 9(1), 34-37.

[6] Association of Official Analytical Chemists (AOAC). (1980). Official methods of analysis, Fifteenth edition. AOAC, Arlington.

[7] Ojokoh AO and Wei Y. (2011). Effect of fermentation on chemical composition and nutritional quality of extrude and fermented soya products, International Journal of Food. Engineering, 7, 4-6.

[8] Ojokoh AO, Oyetayo MA and Ojokoh ES. (2016). Evaluation of Mucuna beans flour fermented with Lactobacillus plantarum as a probiotic food. Journal of Advances in Microbiology, 1(1), 1-11. 
[9] Lawal TE, Ademola SG, Owoseni AA, Atobatele OE and Asuelimen PO. (2017). Aspergillus flavus degraded brewer dried grains for broiler chicken diet: performance and nutrient digestibility Parameters. Journal of Advances in Biology \& Biotechnology, 11(1), 1-8.

[10] Iyayi EA and Aderolu ZA. (2004). Enhancement of the feeding value of some agro-industrial by-products for laying hens after their solid state fermentation with Trichoderma viride. African Journal of Biotechnology, 3(3), 182-185.

[11] Demeke S. (2007). Comparative nutritive value of Atella and industrial brewers grains in chicken starter ration in Ethiopia, Livestock Researh for Rural Development, 19(1).

[12] Balog JM and Miller RI. (1989). Influence of the sense of taste on broiler chick feed consumption. Poultry Science, 68(11), 1519-1526.

[13] Agbede J. (2003). Equiprotein replacement of fishmeal with the leuceana leaf protein concentrate: an assessment of performance characteristics and muscle development in the chicken. International Journal of Poultry Science, 2, 421-429.

[14] Majeed LH, Abdelati KA, El Bagir NM, Mohammed HE and Beynen AC. (2010). Performance of broiler chickens fed diets containing low inclusion levels of black cumin seed. Journal of Animal and Veterinary Advances, 9(21), 2725-2728.

[15] Cossack ZT and Rojhani A. (1972). Fibre in enteral formula: Effects of sugar-beet versus soy fibre on zinc and folic acid absorption in human subjects. Clinical Nutrition, 11, 35-38.

\section{How to cite this article}

Onyimba IA. (2020). Feed value of fermented spent sorghum grains for broiler chickens. World Journal of Advanced Research and Reviews, 6(1), 238-243. 